\title{
A Study on the Impact of Violent Behavior Awareness on Domestic Violence : Focusing on the Social Group Work Intervention Effect
}

\author{
Misook Cho1)
}

\begin{abstract}
This study was designed on the fact that the denial, reduction, justification, and projection of violent behavior by domestic violence offenders are reported as one of the main causes that reduce the effectiveness of treatment. Therefore, the purpose of this study was to investigate how group intervention for violent behavior awareness would change the irrational thinking of domestic violence offenders who were ordered to receive institutional treatment. This study used the one-group pretest-posttest design to conduct a 50-hour Social Group Work program with a PBL-based "cognitive behavioral" approach for ten domestic violence offenders. In terms of the research method, the pre-post group intervention values were measured for changes in violent behavior and irrational thinking, and the Wilcoxon signed-rank test (non-parametric statistical analysis) was used to verify the difference. As a result, the participants' awareness of violent behavior showed a significant difference as the mean value before and after group intervention increased by $7.17(\mathrm{P}<0.001)$. Comparing the pre-post group intervention scores for irrational thinking also showed significant results in all 7 categories $(\mathrm{P}<0.001)$. The implications of the corrective social welfare approach and the limitations of this study were presented based on these findings.
\end{abstract} Work

Keywords: Domestic Violence Offenders, Violent Behavior Awareness, Irrational Thinking, Social Group

\section{Introduction}

According to the statistical yearbook of probation for 2019, the number of domestic violence cases handled by probation offices under the Ministry of Justice increased significantly from 144 to 28,056 since enforcing the Act on Special Cases Concerning the Punishment, etc. of Crimes of Domestic Violence on July 1, 1998[1]. In Korea, social interest in domestic violence has increased since the late 1980s, and interventions to prevent domestic violence have been developed with the opening of shelters and counseling centers by private institutions. A wide variety of studies have been performed on domestic violence, and the denial, reduction,

Received(April 8, 2020), Review Result(1st: May 21, 2020, 2nd: July 9, 2020), Accepted(July 27, 2020)

1) (Professor) 01795, Department of Social Welfare, Sahmyook University, Hwarangro 815, Nowon-gu, Seoul, South Korea

email: joms@syu.ac.kr 
justification, and projection of violent behavior by domestic violence offenders have been recently been reported as one of the main causes that reduce the effectiveness of therapy[2][3]. That is, the denial, reduction, and justification of the offender's violent behavior could be a new point of intervention. Therefore, how to resolve the denial, reduction, and justification of violent behavior by domestic violence offenders remains an important challenge. Edleson's study on intervening with men for violence prevention and Tolman et al.'s study on the continuity of violence also found that anger affects violent behavior, and confirmed that rational thinking training for anger management could play an important role in reducing violent behavior[2][4]. In this respect, studies on the effectiveness of anger management to reduce violent behavior by inducing the awareness of violent behavior related to the prevention and treatment of domestic violence are urgently needed.

Therefore, the purpose of this study is first, to measure the violent behavior awareness and irrational thinking of domestic violence offenders who were ordered to receive institutional treatment, the purpose of this study is second, conduct a focused group program to guide offenders to recognize their own violent behavior, and examine the changes in their irrational thinking about violence.

\section{Theoretical Background}

\subsection{Definition of "Domestic Violence Offender"}

Under the current Act on the Prevention of Domestic Violence and Protection, etc. of Victims, the term domestic violence refers to the act of one family member intentionally inflicting physical or psychological harm to another family member[5]. However, it is not easy to define domestic violence in reality. This is because similar terms are mixed and used among scholars and practitioners, and there are also difficulties in setting the extent or scope of abuse in detail[5].

Therefore, in this study, the term "domestic violence offender" is limited to those who have been ordered by the court to receive more than 50 hours of institutional treatment as a result of 'actions inflicting physical or psychological harm or damage to the property of family members' based on Article 2-1 of the 'Act on Special Cases Concerning the Punishment, etc. of Crimes of Domestic Violence' to specify the scope of the study. 


\subsection{Violent Behavior and Irrational Thinking}

In cognitive-behavioral theory, violent behavior is allayed by reducing stress or anxiety by the offender and is described as the root cause of the offender's irrational aggressive behavior. Cognitive-behavioral theory suggests that violence is learned and reinforced through social learning and that non-violent behavior can be also be learned[2]. Recently, Veneski et al. reported that more than $75 \%$ of offender programs are using cognitive-behavioral models to promote awareness of violent behavior[6]. The reason why domestic violence agencies prefer cognitive-behavioral models is that violence and life-threatening aggressive behavior require short-term, problem-oriented intervention like cognitive-behavioral models.

Therefore, empirical studies continue to reveal that cognitive-behavioral techniques are highly effective in recognizing violent behavior. Moreover, the systematic process of cognitive-behavior stresses the importance of intervention methods and procedures that can help therapists apply techniques and facilitate the participants' learning.

Some of the most notable figures in cognitive therapy include Aaron T. Beck, David D. Burns, Albert Ellis, and Mark R. McMinn. This study focuses on Burns' theory of cognitive therapy as a result of comparing the irrational thinking process of the four scholars[7][8]. The reason for this is that, first, their emphasis is consistent even though their methods somewhat vary, and second, their methods are clear and effective, which is why they are used to change the irrational thinking of domestic violence offenders and help them realize their aggressive behavior. According to Burns, the basic principles of cognitive therapy are that 'our thoughts and beliefs create our moods, so our thoughts can be predicted through our mood.' In particular, negative emotions are caused by negative thoughts, and, as these negative thoughts contain major distortions, thinking more rationally will make one feel better[7][8].

Burns specified 7 major irrational thoughts (approval, love, achievement, perfectionism, entitlement, omnipotence, autonomy). McMinn specified 3 irrational thoughts (sympathetic belief, obsessive belief, controlled belief) to present the following 3 steps to identify automatic thoughts: Step 1: Notice the specific situation or event, Step 2: Notice your emotions, Step 3: Identify your thoughts. Therefore, it is critical for domestic violence offenders who have been ordered to receive institutional treatment to realize that domestic violence is a punishable crime and to recognize the reality of violence[9]. Therefore, this study examined how Burns' 7 irrational thinking frameworks have changed before and after measuring the effectiveness of the Social Group Work intervention focusing on the participants' awareness of violent behavior. 


\subsection{Social Group Work for Violent Behavior Awareness}

Groups provide support systems for emotionally isolated people and allow them to learn how to rely on others in stressful situations. Therefore, the Social Group Work for domestic violence offenders has 4 main purposes: 1) Ensure the safety of the victims, 2) Change the offender's attitude toward violence, 3) Enhance the offender's sense of responsibility, 4) Learning non-violent alternatives for past behavior[2]. Currently, the Duluth model, which focuses on power and control, as well as the anger management model to understand and control anger are effectively used as social group work models[10].

To achieve this goal, most groups use a combination of anger management, stress reduction, communication skills, and gender re-socialization[10-12]. Also, group intervention programs typically consist of educational structured learning experiences, where PBL (Problem-Based Learning) is used to improve the educational effect of the participants and to help the participants find answers to their own problems through active participation. Barrows defines PBL as the learning that results from the process of working toward the understanding or resolution of a problem.' The major effects of PBL include acquiring integrated knowledge about the body related to the problem and applying and developing problem-solving functions[13].

As per the above, various models have been applied for clinical interventions for domestic violence offenders, but there has been a lack of discussion on which model should be used and how to approach them effectively in Korea. Therefore, in terms of the current court order system against violence, discussions on how to conduct an intervention for domestic violence offenders will be a foundation for developing and implementing programs in the future.

\section{Research Method}

\subsection{Participants}

The participants of this study are domestic violence offenders who have been ordered by the court to receive more than 50 hours of institutional treatment. In terms of the group program, 10 people participated until the end of the study with 3 exceptions: 2 participants dropped out in the middle of the program because their court order hours were shorter than those required by the other participants, and 1 person was absent during the post-evaluation. The intervention period was from the first week of September to the third week of November 2019. 
This study conducted a PBL-based Social Group Work program for violent behavior awareness with a co-host. The program consisted of 16 sessions, which were held twice a week for 6 hours. The program also used cognitive behavioral treatment models and allocated a certain amount of time to roleplays, discussions, and developing concepts and thoughts to maximize effectiveness and to allow the offenders to recognize their violent behavior[14].

\subsection{Design}

It was not easy to organize a control group in this study because the participants consisted of those who have been ordered by the court to receive more than 50 hours of institutional treatment. Therefore, the one-group pretest-posttest design was used to verify changes in the factors for violence before and after program intervention and setting the participants in the group program as the experimental group.

\subsection{Research Method}

The data was analyzed using SPSS/WIN, and the Wilcoxon signed-rank test (non-parametric statistical analysis) was used to verify the difference in the values for violent behavior awareness and irrational thinking before and after group intervention because of the small number of cases. The measurement tools used in this study are as follows.

\subsubsection{Basic Cognitive Ability Test of Participants}

MMSE-K was used to measure the basic cognitive abilities of the participants[15]. MMSE-K is a standardized tool that is reliable and valid. MMSE-K consists of 12 questions in temporal orientation (5 points), spatial orientation (5 points), registration ( 3 points), attention and calculation (5 points), language function (7 points), understanding and judgment ( 2 points), with a maximum score of 30 points. All of the participants of this study received a total score of more than 25 , so there were no problems in participating in the study.

\subsubsection{Irrational Thinking}

Burns said that one could tell which irrational thoughts he or she has according to the 7 irrational thought patterns, and the more positive the score, the more rational thinking to recognize and control violent behavior. The questionnaire consists of a total of 35 questions, 
which are divided into 5 questions in 7 categories (approval, love, achievement, perfectionism, entitlement, omnipotence, autonomy). The reliability in this study was Cronbach $a=.88$.

\subsubsection{Violent Behavior Awareness}

The violent behavior awareness scale is divided into the victim's aspect, the offender's aspect, and the children's aspect, and the higher the score, the higher the awareness of domestic violence. The questionnaire consists of 17 reverse-scored items. This scale was used to measure the change of violent behavior awareness before and after the program and the reliability in this study was Cronbach $a=.89$.

\section{Result Analysis}

\subsection{General Characteristics of the Participants}

The average age of the participants of the group program was 43.1 with 4 people in their $40 \mathrm{~s}$ and the education level of 7 participants was high school graduates or higher. The occupations of the participants were evenly distributed, including self-employed, day laborers, sales positions, and employment services. Seven people were in their first marriage with their wives. Two participants remarried and one participant was unmarried.

[Table 1] General characteristics of the participants

\begin{tabular}{|c|c|c|c|c|c|}
\hline No. & Age & $\begin{array}{c}\text { Gend } \\
\text { er }\end{array}$ & Education & Occupation & Court order hours \\
\hline \hline Case 1 & 47 & $\mathrm{M}$ & High school graduate & Proprietor, karaoke venue & $50 \mathrm{hrs}$ \\
\hline Case 2 & 43 & $\mathrm{M}$ & High school graduate & Self-employed & $50 \mathrm{hrs}$ \\
\hline Case 3 & 37 & $\mathrm{M}$ & High school graduate & Proprietor, design company & $50 \mathrm{hrs}$ \\
\hline Case 4 & 28 & $\mathrm{M}$ & High school graduate & Unemployed & $50 \mathrm{hrs}$ \\
\hline Case 5 & 27 & $\mathrm{M}$ & University graduate (4-year) & Part-time employee, bar & $50 \mathrm{hrs}$ \\
\hline Case 6 & 44 & $\mathrm{M}$ & College graduate (2-year) & Proprietor, security company & $50 \mathrm{hrs}$ \\
\hline Case 7 & 51 & $\mathrm{M}$ & High school dropout & Construction (rebar) & $50 \mathrm{hrs}$ \\
\hline Case 8 & 50 & $\mathrm{M}$ & Elementary school graduate & Simple labor & $50 \mathrm{hrs}$ \\
\hline Case 9 & 42 & $\mathrm{M}$ & Middle school graduate & Transportation & $50 \mathrm{hrs}$ \\
\hline Case 10 & 65 & $\mathrm{M}$ & University graduate (4-year) & Unemployed & $50 \mathrm{hrs}$ \\
\hline
\end{tabular}

\subsection{Pretest-posttest for Violent Behavior Awareness}

The Wilcoxon signed-rank test was conducted to verify changes in the violent behavior 
awareness of domestic violence offenders before and after participating in the program. The number of cases of Negative Ranks, which means that violent behavior awareness decreased after the group program, was 0 and the mean rank was 0 . In contrast, the number of cases of Positive Ranks, which means that violent behavior awareness increased after the group program, was 10 and the mean rank was 5.50. This means that all of the participants showed statistically significant changes in violent behavior awareness after the program, which shows a positive change. The pre-post mean value test also showed a significant difference from 47.25 to 54.42 .

[Table 2] Pre-post Test of Violent Behavior Awareness

\begin{tabular}{|c|c|c|c|c|}
\hline & Case & $M$ & $\mathrm{Z}$ & $\mathrm{P}$ \\
\hline Negative Ranks & 0 & & \multirow{3}{*}{-2.805} & \multirow{3}{*}{$\begin{array}{c}0.001 \\
* * *\end{array}$} \\
\hline $\begin{array}{c}\text { Positive Ranks } \\
\text { Ties }\end{array}$ & $\begin{array}{c}10 \\
0\end{array}$ & 5.50 & & \\
\hline Total & 10 & & & \\
\hline
\end{tabular}

${ }^{*}: \mathrm{p}<0.05, \quad * *: \mathrm{p}<0.01, \quad * * *: \mathrm{p}<0.001$

[Table 3] Pre-post Mean Value Test of Violence Awareness

\begin{tabular}{|c|c|c|}
\hline & Mean score & P \\
\hline Pre & 47.25 & 0.001 \\
Post & 54.42 & $* * *$ \\
\hline
\end{tabular}

${ }^{*}: \mathrm{p}<0.05, \quad{ }^{* *}: \mathrm{p}<0.01, \quad * * * \mathrm{p}<0.001$

\subsection{Pretest-posttest for Irrational Thinking}

The Wilcoxon signed-rank test was conducted to verify the subjects' changes in irrational thinking of domestic violence offenders before and after participating in the program, and the results are shown in [Table 4] and [Table 5].

[Table 4] Pre-post Test of Irrational Thinking

\begin{tabular}{|c|c|c|c|c|}
\hline & Case & M & Z & P \\
\hline $\begin{array}{c}\text { Negative Ranks } \\
\text { Positive Ranks }\end{array}$ & 0 & & & \\
Ties & 10 & 5.50 & \multirow{2}{*}{-2.704} & $0.001^{* * *}$ \\
\cline { 1 - 2 } Total & 10 & & & \\
\hline
\end{tabular}

$*: \mathrm{p}<0.05, \quad * *: \mathrm{p}<0.01, \quad * * *: \mathrm{p}<0.001$ 
According to the changes in the pre-post test of irrational thinking, the number of cases of Positive Ranks, which means that the distorted cognitive system showed positive change after the intervention, was 10 and the mean rank was 5.50. On the other hand, the number of cases of the Negative Ranks was 0, which was statistically significant.

[Table 5] Pre-post Test of Irrational Thinking Mean Values

\begin{tabular}{|c|c|c|c|c|c|c|c|c|}
\hline & Approval & Love & Achievement & Perfectionism & Omnipotence & Entitlement & Autonomy & P \\
\hline Pre & -3.50 & -4.60 & -1.00 & -1.90 & -2.70 & -3.20 & -0.80 & 0.001 \\
\hline Post & +0.40 & +2.10 & +4.30 & +1.50 & +1.50 & +1.30 & +4.00 & $* * *$ \\
\hline
\end{tabular}

${ }^{*}: \mathrm{p}<0.05, \quad * *: \mathrm{p}<0.01, \quad * * * \mathrm{p}<0.001$

\section{Conclusion and Suggestions}

The purpose of this study was to examine how Social Group Work intervention for violent behavior awareness would change the irrational thinking of domestic violence offenders who were ordered to receive institutional treatment. A 50-hour Social Group Work program with a cognitive behavioral model approach was conducted for 10 domestic violence offenders using the one-group pretest-posttest design. In terms of the research method, the pre- and post-group intervention values were measured for changes in violent behavior awareness and irrational thinking and the Wilcoxon signed-rank test (non-parametric statistical analysis) was used to verify the difference.

As a result of comparing the scores before and after group intervention, the mean value of the participants' awareness of violent behavior increased by $7.17 \quad(\mathrm{P}<0.001)$, showing a significant difference. The results of comparing the pre-post scores for irrational thinking also showed significant results in all 7 categories. Therefore, conducting a cognitive behavioral therapy group program focusing on PBL educational principles proved to be useful in positively changing the irrational thinking system of domestic violence offenders such as the denial, reduction, justification, and projection of violent behavior.

Nevertheless, the limitations of this study were as follows. First, it was difficult to organize a control group because the group program was conducted for domestic violence offenders who have been ordered by the court to receive more than 50 hours of institutional treatment. Second, the participants were set as the experimental group and the one-group pretest-posttest study design was used to verify changes in the factors for violence before and after the program. Consequently, there are various limitations to generalize the results. Third, even after using non-parametric testing, there are difficulties in generalizing the study results by statistical 
processing quantitative data collected from only 10 participants. Therefore, various research results need to be accumulated. Fourth, this study was designed by considering the research results in other countries. These results specifically report the denial, reduction, justification, and projection of violent behavior by domestic violence offenders as one of the main causes that reduce treatment effect. As such, more in-depth research design and more studies need to be performed to determine whether the results reported from other countries are applicable to Korean culture.

Based on these findings, the implications of a corrective social welfare approach are as follows[16][17].

First, with professional interventions based on various theories that are becoming more active, it is necessary to accept a wider range of academic theories and promote research. We must also be very careful when intervening to resolve the problems of domestic violence offenders.

Second, most of the institutional treatment orders in Korea are designated for about 50 hours, which is very short compared to protective disposition training conducted for more than 30 weeks in the US or the United Kingdom. Accordingly, it is difficult for the participants to change their irrational thinking patterns through violent behavior awareness during this shorter period. It is thus necessary to differentiate the duration of institutional treatment according to the domestic violence offender's degree of aggressive behavior.

Third, when an incident occurs and is reported, the police are dispatched to the scene and the case is handled through investigations and trials by the prosecution and court. However, ecological system management and education are needed from the onset of the incident to follow-up management after the case is closed to reduce the number of second and repeat offenders.

Therefore, participation in education programs should be purely voluntary, and it would be more effective if the offender's family members can also participate. In particular, programs should be developed and used to foster leaders who can provide support and treatment in various aspects for the whole family and to train specialized leaders in each region.

\section{Acknowledgement}

This paper was supported by the Sahmyook University Research Fund in 2020. 


\section{References}

[1] Ministry of Justice, Statistical yearbook of probation, Korea: Ministry of Justice, (2019)

[2] Tolman, Edleson, Intervening with men for violence prevention, Sourcebook on Violence Against Women, 2nd Edition, USA CA: Sage Publications, (2016), pp.351-367.

[3] Juliana Carlson, Erin Casey, Jeffrey L. Edleson, Strategies to engage men and boys in violence prevention: A global organizational perspective, Violence Against Women, (2015), Vol.21, No.11, pp.110-168. DOI: https://doi.org/10.1177/1077801215594888

[4] Jeffrey L. Edleson, Groupwork with Men Who Batter: What the Research Literature Indicates, USA: National Resource Center on Domestic Violence (NRCDV), (2012)

[5] Misook Cho, Correctional Social Work, Korea: Yangseowon Publisher Book, (2013)

[6] Veneski, Lindhorst, Edleson, U.S. Judicial implementation of the Hague Convention in cases alleging domestic violence, Juvenile and Family Court Journal, (2018). Vol.62, No.1, pp.1-21, DOI:10.1111/j.1755-6988.2011.01058.x

[7] Beck. A. T., Cognitive Therapy and the Emotional Disorders, USA: SAGE Publisher, (2018)

[8] McMinn, Mark R., Psychology, Theology, and Spirituality in Christian Counseling, USA: Tyndale House Publishers, (2018), pp.104-127.

[9] Sonkin, Dutton, Treating Assertive men from an attachment perspective, Journal of Aggression, Maltreatment, A Trauma, (2013), Vol.7, No.2, pp.105-133.

[10] Hamby. S., Battered Women's Protective Strategies: Stronger Than You Know (Interpersonal Violence), UK: Oxford University Press, (2013), pp.112-137.

[11] Dutton, E., How to Judge People by What They Look Like, USA: SAGE Publisher, (2018), pp.277-301.

[12] Gondolf. E. W., Gender-Based Perspectives on Batterer Programs: Program Leaders on History, Approach, esearch, and Development, USA: SAGE Publisher, (2015), pp.7-289.

[13] Barrows, Tamblyn, Problem-based learning: An approach to medical education, German: Springer Publishing Company, (2012), pp.18-39.

[14] Neighbors, Walker, Mbilinyi, O'Rourke, Edleson, Zegree \& Roffman, Normative misperceptions of abuse among perpetrators of intimate partner violence, Violence Against Women, (2010), Vol.16, No.4, pp.370-386.

[15] MMSE-K (Mini-Mental State Examination), https://new.neuro.or.kr/file/K-MMSE_20171127.pdf, Nov 27 (2017)

[16] Misook Cho, A Comparative Study on the Impact of Domestic Violence According to Children's Gender, Asia-pacific Society of Convergent Research Interchange, (2019), Vol.5, No.4, pp.113-122.

[17] Misook Cho, A Study on The Psycho-Social Disturbance of Children Who Are Exposed to Domestic Violence : Focusing on Hierarchical Analysis Verification, Asia-pacific Society of Convergent Research Interchange, (2018), Vol.4, No.3, pp.31-42. 